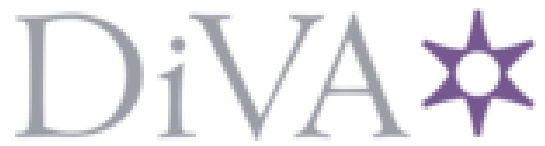

http://www.diva-portal.org

Preprint

This is the submitted version of a paper published in International Journal of Product Development.

Citation for the original published paper (version of record):

Massimo, P., Bertoni, M., Johansson, C. (2020)

Value models: coordinating artefacts for conceptual design

International Journal of Product Development, 23(4): 326-352

https://doi.org/10.1504/IJPD.2019.105490

Access to the published version may require subscription.

N.B. When citing this work, cite the original published paper.

Permanent link to this version:

http://urn.kb.se/resolve?urn=urn:nbn:se:bth-19264 


\title{
Value models: coordinating artefacts for conceptual design
}

\begin{abstract}
This paper contributes to the discussion on value models as decision support in early design. Emerging from data collected through semi-structured interviews with 20 professionals in 3 manufacturing companies, the paper highlights the limitation of current development practices to promote cross-functional knowledge sharing about the stakeholders' lifecycle expectations to be met. This limits the ability to make decisions about aspects of value that are difficult to assess and quantify. The objective of the paper is then to propose the use of value models as 'boundary objects' to increase shared awareness about the design intent, triggering negotiations towards more value-adding design decisions. This role of the value model as a boundary object is studied through design experiments, using a combination of protocol analysis and observation technique on the video-recorded material.
\end{abstract}

Keywords: Value Models, Value Driven Design, Boundary Objects, Engineering Design, Conceptual Design, Cross-functional collaboration. 


\section{Introduction}

The evolution of society is pushing manufacturing companies towards developing sustainable 'solutions' able to cope with increasingly sophisticated customer expectations and needs. Such novel business approaches - developed around the notion of 'servitization' (Tan et al., 2010) - involve a radical change in the way engineering design activities are approached.

Traditionally, engineers are focused on meeting objectives related to the functionality and the cost of realization of a product (Ulrich \& Eppinger, 2011). When developing servitized 'solutions' engineers need to embrace a more holistic approach, emphasizing what ultimately brings value to the customers and the stakeholders (Coley \& Lemon, 2008). In servitization the concept of value is essential (Baines et al. 2007), and it is appealing to think about using value as a driver for making early design decisions. Since engineers often use models to support their decision-making, there is a growing interest in how to model 'value' in so-called 'value models' (Isaksson et al., 2009).

Despite this growing interest, the nature of value models and how they should be built is still under debate (Soban et al., 2011; Bertoni et al., 2019). This is because engineers require tangible metrics for making decisions, traditionally represented by explicitly expressed design requirements (such as weight, cost, performances etcetera). "Value" is instead difficult to express explicitly through requirements, since it contains a great deal of "tacit" or ill-defined expectations, such as being "sustainable" or "easily maintainable". As a consequence, only a part of the original needs and expectations of a system (i.e., its design intent) is translated into requirements (Collopy \& Hollingsworth, 2011). For large and technically complex systems the gap between the original intent and the technical solutions is large. To include "tacit" expectations in the early design phase, engineers often need to rely on their ability to develop a shared meaning with members coming from other organizational functions (Larsson, 2003).

There is a need to understand how a value model shall be configured to enable a crossfunctional design team to achieve a more collective ownership of objectives and tradeoffs. In literature, such decision supports are identified around the theoretical constructs of 'boundary objects' (Star \& Griesemer, 1989) and coordinative artefacts (Schmidt \& Wagner 2002).

Elaborating on these considerations, this research has focused on the following research question:

RQ: What are the characteristics that promote the use of value models as coordinative artefacts (or boundary objects) in early design?

Knowing this can provide insights into what factors should be taken into account when building value models in the early design phases.

\section{Literature review}

This section elaborates on the challenges related to value-oriented decision-making in early design, and how novel approaches have emerged in the recent years to cope with these challenges. It also provides an overview about the literature related to boundary objects and coordinative artefacts in early design. 


\subsection{The challenge of deliberating about 'value' in early design}

When making decisions in product development, value plays a central role (Ulrich \& Eppinger, 2011). However, the practical means for adopting value as a basis for decision-making are less straightforward. Engineers require tangible metrics for making design decisions, especially to be able to solve trade-offs between the oftenconflicting objectives that characterize a product along its lifecycle. These metrics are traditionally represented by design requirements (such as weight, cost, performances etcetera). Ideally, requirements are clear, and the development of a complex system is a step-by-step transformation of requirements into specifications for a design (Fabrycky \& Blanchard, 1991).

Research in systems engineering (e.g., Durugbo \& Riedel, 2013) find this view too simplistic and not reflecting the reality of complex product development. Under the assumption that design problems are "ill-defined" (Cross et al., 1996), it is difficult to capture and synthetize the original needs and expectations of a product through requirements (Collopy \& Hollingsworth, 2011). In addition, 'servitization' (Tan et al., 2010) and Product-Service Systems (PSS; Shimomura \& Arai, 2009; Cavalieri \& Pezzotta, 2012) increase the manufacturers' level of responsibility in the late stages of the product lifecycle, intensifying the level of risk related to the operational, maintenance and disposal stages (Isaksson et al., 2009). So-called 'downstream' lifecycle properties (e.g., serviceability and remanufacturability) need to become an integral part of the decision-making process since the early design phases (Charnley et al., 2011). However, downstream properties entail a number of tacit concepts that are difficult to model, simulate, and optimise in the same way as more traditional engineering objectives (e.g., functionality, weight, and structural robustness) (Raudberget et al., 2015). For this reason, these downstream lifecycle properties - often labelled as non-functional requirements of "ilities" (McManus et al., 2007) - are difficult to trade against more traditional design targets, being often down-prioritised (or even neglected) during early design trade-offs (Isaksson et al., 2009).

\subsection{Value models as support for early stage decision making}

The need to simultaneously balance diverse and multidisciplinary stakeholder needs and expectation has resulted in a number of methodological approaches. Value Driven Design (VDD; Collopy \& Hollingsworth, 2011) is research initiative that seeks to bring value into explicit drivers for engineering design. According to original formulations of VDD, design decision-making should be based on the maximization of an objective function (Browning, 2003), which gives information on how much customers 'value' certain capabilities over others (Wierzbicki et al., 2000). For instance, increasing a vehicle weight leads to increased fuel costs, but may result in longer maintenance intervals and reduce costs that way (Price et al., 2012). In the early formalizations of VDD, the concept of optimization is pivotal. Collopy \& Hollingsworth (2011) envision the idea that the best design option can be the result of the mathematical optimization of a financial objective function, or 'value model'. Such function can then be used as a tool for guiding the resolution of design trade-offs. Several authors (e.g.; Cheung et al., 2012) have applied value models with a financial objective function that combines the 
attributes of a system that produces the 'best' overall economic value in a lifecycle perspective.

A major problem with deterministic and monetary value models is that they are too data-intensive and difficult to build in the early design phases (Soban et al., 2011). This results in severe issues related to their 'reliability' for decision making (Soban et al., 2011), mainly because such lack of trust impede communication among decision makers (Collopy, 2012). This is the reason why a part of the VDD literature favours the use of more qualitative models (e.g., Soban et al., 2011; Isaksson et al., 2013). Qualitative value models are more easily constructed, populated and shared than deterministic ones, facilitating the capture of the 'rationale' behind a design solution. This has been demonstrated in research projects within aerospace. For example, Eres at al. (2014) focused on mapping the value attributes of a system onto key engineering characteristics by extending the Quality Function Deployment (QFD) method with the use on non-linear correlations functions - the EVOKE model (Bertoni et al., 2018). Qualitative value models, such as EVOKE, can be utilized much earlier that mathematical optimization models, emphasizing subjective and intangible aspects such as ilities (McManus et al. 2007), personal factors (Grönroos \& Voima, 2013), and sustainability integration (Hallstedt et al. 2015). This is advantageous because it facilitates the iterative and collaborative development of design requirements (Monceaux \& Kossman, 2012).

For these reasons, literature on VDD slightly shifted their viewpoints from the original formulation of VDD and its orientation towards mathematical optimization. In particular, literature stresses the importance of value models beyond their use as means for design optimization, particularly pointing at their benefits in facilitating multidisciplinary (or cross-functional) collaboration in early design. Still, there is a need to increase the understanding of how value models shall be configured to enable a cross-functional design team to achieve a more collective ownership of objectives and trade-offs in early design (Soban et al., 2011; Bertoni et al., 2019).

\subsection{Coordinative artefacts as support for cross-functional decision making}

Teamwork and social interaction are fundamental for good decision making (Kleinsmann et al., 2012), specifically in concept selection (Toh \& Miller, 2015). Yet, team members often struggle to reach a shared understanding of the domain, the requirements, the roles and the objectives of a design (Bucciarelli, 2002; Ensici et al., 2013). In this context, objects or representations are common collaboration enablers (Larsson, 2003).

Representations (such sketches, assembly drawings, prototypes and computer simulations) are fundamental for design communication they can be used as 'coordinative artefacts' (Schmidt \& Wagner 2002). Despite the benefits of using representations for collaboration, their use can also hinder the negotiation process. Carlile (2002) demonstrated how discipline-specific representations cause errors and delays when shared with professionals from other disciplines. As these models represent mainly the perspectives of the discipline that created them, it is difficult for others to visualise their own concerns within the same object. To avoid these communication bottlenecks (Eckert, 2001), much of the literature stresses the notion of 'boundary objects', which identifies the types of representations that have 'different meanings in different social worlds but their structure is common enough to more than 
one world to make them recognisable as a means of translation' (Star \& Griesemer, 1989: p. 393). Research has provided useful insights into the role of representations as coordinative artefacts (or boundary objects) during early design (Becattini \& Cascini, 2014). For example, literature (e.g., Krogstie \& Divitini, 2007; Rahi Rasoulifar et al., 2008; Imre, 2015) points to the benefits of using requirements lists (Pahl \& Beitz, 2013) as boundary objects to specify the design assignment (defining the problem space) and to constraint the desired solution (exploring the solution space) (Brace et al., 2010). Requirements are often given in narrative format and contain a metric and a measurable target (Pahl \& Beitz, 2013).

Emerging from these studies this paper investigates how value models can be configured to further enhance cross-functional decision making in early design, and how such 'coordinate artefacts' would influence the designer's behaviour if provided to the decision makers in a 'servitization' and Product-Service System context.

\section{Research Methodology}

This research has investigated the role of a value model as support for cross-functional decision-making. The means of data collection of this study are focused on: 1) one empirical study, featuring semi-structured interviews with industrial practitioners and 2) experiments with audio- and video-recorded design episodes - using verbal protocol analysis (Gero and McNeill 1998) - that involved a total of 22 students.

\subsection{Empirical study}

The first source of data for this study entails the analysis of semi-structured interviews with industrial practitioners, in collaboration with 3 major Swedish companies:

- Company A is a road construction equipment manufacturer, part of a global multinational company that has experience with different types of bundled product-service offerings.

- Company B is a construction equipment company that is currently investing in the development of integrated customer solutions.

- Company $\mathrm{C}$ is a first-tier supplier of aero structures and engine products, where different types of PSS-like offers are proposed.

The three companies are considered interesting for this study as all three are currently developing bundled product-service offerings, which draw their attention to invest in novel decision-based supports that promote the inclusion of more downstream lifecycle properties in the early design phase of the hardware.

The main aspects of interest during the interviews were to understand the respondents' perceptions of how they deal with 'value' when making design decisions, and about the role of 'value' during the collaboration between different parts of the organization (i.e., marketing, engineering, aftermarket, service solutions). A total of 20 practitioners were interviewed, the majority of them holding managerial positions at their respective company, both in R\&D and new business development. All interviews were recorded, transcribed, and validated with the respondents. Relying solely on interviews can limit the completeness of the dataset. A more complete dataset may be obtained by observing 
model use in the design process with observations and ethnography methods. Observation is certainly a powerful and reliable method but is extremely demanding of research resources when decision processes span a long-time period (Mintzberg et al., 1976), such as in the case of product development projects. Therefore, researchers were obliged to rely heavily on interviews

The analysis of the recorded interview transcripts was conducted using a coding scheme (Strauss \& Corbin, 1990). This study used a mixed deductive-inductive coding approach (Miles \& Huberman, 1994). A provisional list of codes was created based on the key variables of interest. Additional codes were added as the coding activity proceeded.

Strauss \& Corbin (1990) suggest to start the inductive coding activity by categorizing the data into generic themes 'conditions', 'interaction among actors', 'strategies and tactics', and 'consequences'. These themes were defined based on studies about effective objects for cross-functional collaboration (e.g., Carlile 2002; Larsson 2003).

Table 1: List of categories applied for the analysis of the interviews.

\begin{tabular}{|c|c|c|}
\hline Theme & Code & Definition and rationale \\
\hline Conditions & $\mathrm{CON}$ & $\begin{array}{l}\text { This code refers to the circumstances or factors affecting the way in which a } \\
\text { cross-functional team makes decisions, such as the complexity of the supply } \\
\text { chain or the availability of decision supports or models. }\end{array}$ \\
\hline $\begin{array}{l}\text { Interaction among } \\
\text { actors }\end{array}$ & INT & $\begin{array}{l}\text { This code refers to the reciprocal actions, communications or influences } \\
\text { among the members of the cross-functional teams, as reported by informants. }\end{array}$ \\
\hline Strategies and tactics & STRA & $\begin{array}{l}\text { This code refers to a plan of action designed to achieve a long-term or overall } \\
\text { aim. This code captures specifically the impact that developing 'servitized' } \\
\text { solutions (or PSS) has on the ways a cross-functional team needs to } \\
\text { collaborate and make decisions during the design of the hardware. }\end{array}$ \\
\hline $\begin{array}{l}\text { Consequence - } \\
\text { Efficacy of trade-off } \\
\text { identification }\end{array}$ & EFF-ID & $\begin{array}{l}\text { This code refers to the duration of trade-off identification (i.e., how early in the } \\
\text { design process trade-offs are identified). According to Iorio \& Taylor (2014), } \\
\text { investigating both the trade-off identification and resolution stages of a } \\
\text { negotiation process can reveal insights about the efficacy of models in } \\
\text { collaborative work. }\end{array}$ \\
\hline $\begin{array}{l}\text { Consequences } \\
\text { Efficacy of trade-off } \\
\text { resolution }\end{array}$ & EFF-RES & $\begin{array}{l}\text { This code refers to the the duration of trade-off resolution. According to Iorio } \\
\& \text { Taylor (2014), investigating both the trade-off identification and resolution } \\
\text { stages of a negotiation process can reveal insights about the efficacy of models } \\
\text { in collaborative work. }\end{array}$ \\
\hline
\end{tabular}

The initial list of categories, their definitions and references used are described in Table 1.

\subsection{Experimental analysis}

The following sections introduce the experiment set-up, the models/supports compared (value model and requirement checklist), the hypothesis for the experiment, and the method used for experimental analysis. 


\subsubsection{Experiment set-up}

Experiments were conducted to further investigate the initial research questions. The experiments featured 6 separate sessions (design episodes) that involved a total of 22 students from the second year's master course in mechanical engineering, industrial economy and sustainable product-service system innovation at the authors' university institution. Students were divided into teams (composed either of 3 or 4 individuals). The students were allocated into the teams so that at least three students in every team were coming from the three different master programs. The rationale for this choice was to mix competencies and backgrounds in order to replicate, although in a scaled down version, those conditions faced by cross-functional teams.

The design assignment was to redesign the front frame and drum of a small asphalt compactor (figure 1), taking into account the manufacturer shift in the business scenario from a from a 'one-sale' model to a 'servitized' (or PSS) offering in which the customers pay proportionally for the provided functionality (i.e. compacted square metres). In this new business model, the manufacturer retains ownership of the equipment and ensures availability of the function by taking care of maintenance and repair operations. This means that such 'servitized' solution intensifies the need for 'downstream' lifecycle aspects, which are difficult to trade and negotiate against more traditional engineering objectives (e.g. weight, structural integrity).

The experiment featured a 20-minute introduction, followed by a 25 -minute design session where the teams were asked to reason on the given design problem and generate ideas and solution strategies. This activity was followed up by an additional 20 -minute session, where the teams had the opportunity to transform their ideas into a product concept and document their final design. The overall problem context was common for all teams. In order to redesign the asphalt compactor sub-systems in the new PSS business scenario, the students received during the introduction information about two previous designs for the frame and drum: the "old frame and drum" (the old, out-dated design) and an improved version, the "current frame and drum" (the As-Is design) (figure 1).
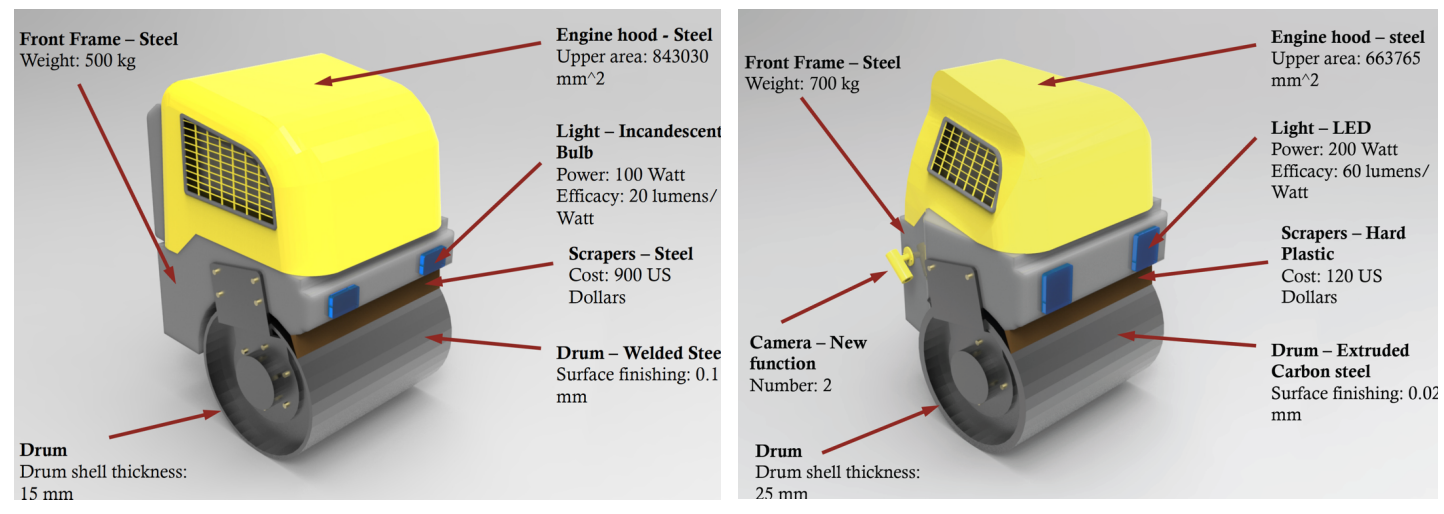

Figure 1: The old version (left) and the current version (right) of the frame and drum.

The purpose was to stimulate students in discussing strengths and weaknesses of these two options, and from these reflections to develop and document a third concept for both sub-systems. While the overall machine architecture remained the same for both 
options, detailed in five main components (drum, frame, engine hood, scrapers, lights). The current design differed from the old one in terms of six engineering characteristics (such as material, geometry or lighting power) and because of the addition of new components (two video cameras directed towards the drum edge). As additional input, all teams received simplified CAD representations of the frame and drum, for both the old and the current design (figure 1). The information package provided to the students included also an assessment report which differed between the design teams is the only object of study for the experiment. The next section introduces the two different types of assessment reports provided to the teams.

\subsubsection{Models/assessment reports compared and hypotheses}

At the beginning of the design session participants received further information which aimed at clarifying directions for the improvement of the frame and drum. This information was given in the form of an assessment report (Table 2) and was different between the teams:

- Three teams received a requirement checklist (Table 2-a) following a traditional representation to guide design choices in product development (Ulrich \& Eppinger, 2011). This type of representation is described in literature as a 'boundary object' in early design (Becattini \& Cascini, 2014). In the requirements checklist, eight initial customer statements were translated into machine target requirements, which were further cascaded down to 51 target requirements for the sub-systems. These included technical considerations (weight, geometry, light power) costs (manufacturing, maintenance) and new functionalities (e.g. cameras). In Table 2-a an excerpt of the provided requirements checklist is provided, displaying the target requirements for the 'current frame and drum'. In this way, the team could assess how close the AsIs design was from the target requirements.

- The remaining three groups received input information in the form of a value model (Table 2-b displays an excerpt), derived from the empirical study findings and the literature review. Details are provided below.

While different approaches for qualitative value modelling exist (described in section 2.2), most models liken a scoring table that ranks a design along a set of attributes (Eres et al., 2014). One of the differences of a value model compared to a requirements checklist is considered to lie in the attributes used to guide the decision process (Bertoni et al., 2018). As mentioned in section 2.2., "tacit" or ill-defined expectations such as being "sustainable" or "easily maintainable" are difficult to express explicitly through requirements in an early design stage. For this reason, Isaksson et al. (2013) have introduced the model constructs 'value drivers' (VDs), indicating key engineering characteristics that impact the Stakeholder needs. VDs are not assigned to a target value or function, but they can be refined into measurable objectives and later, based on these, in requirements. VDs answer the question: "which engineering aspects impact a specific need - that we can control during design?". For example, to increase the lifetime engineers can increase the lifetime of the components by enhancing the thermal capacity and structural integrity of materials. Another strategy would be to relieve the component from life limiting conditions. In this case, the engineer can increase lifetime 
by choosing another design solution, not necessarily increase the thermal capacity of the material.

Table 2: Excerpts from requirements checklist (a) and semi-quantitative value model (b).

(a)

\begin{tabular}{|c|c|c|c|c|c|c|c|c|}
\hline \multirow[b]{2}{*}{$\begin{array}{l}\text { Customer } \\
\text { statements }\end{array}$} & \multirow[b]{2}{*}{$\begin{array}{l}\text { Machine } \\
\text { Requirement }\end{array}$} & \multirow[b]{2}{*}{ Target Requirement } & \multicolumn{6}{|c|}{ Current state of the requirement } \\
\hline & & & 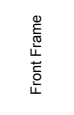 & 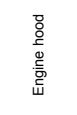 & 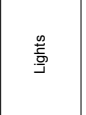 & 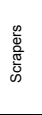 & 结 & 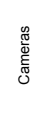 \\
\hline \multirow{2}{*}{$\begin{array}{l}\text { Increase } \\
\text { productivity }\end{array}$} & \multirow{2}{*}{\begin{tabular}{|l|} 
The machine shall be \\
able to compact an area \\
of 4 square meters and \\
$50 \mathrm{~mm}$ deep in one pass \\
\end{tabular}} & The Frame shall weight more than $800 \mathrm{~kg}$ & $700 \mathrm{~kg}$ & & & & & \\
\hline & & The drum width shall be of $1000 \mathrm{~mm}$ & & & & & $1000 \mathrm{~mm}$ & \\
\hline \multirow{2}{*}{$\begin{array}{l}\text { Increase } \\
\text { compaction } \\
\text { quality }\end{array}$} & \multirow{2}{*}{$\begin{array}{l}\text { The machine shall be } \\
\text { able to compact asphalt } \\
\text { with high degree of } \\
\text { finishing }\end{array}$} & The Frame shall weight less than $400 \mathrm{~kg}$ & $700 \mathrm{~kg}$ & & & & & \\
\hline & & The Drum shell finishing shall be less than $0.02 \mathrm{~mm}$ & & & & & $0.02 \mathrm{~mm}$ & \\
\hline \multirow{9}{*}{\begin{tabular}{|l|} 
Reduce \\
operational \\
inefficiencies
\end{tabular}} & \multirow{9}{*}{$\begin{array}{l}\text { The driver shall } \\
\text { perform one } \\
\text { kilometer } \\
\text { compaction in a } \\
\text { narrow city area } \\
\text { without stops }\end{array}$} & $\begin{array}{l}\text { The plan (upper) area of the Front Frame shall be of a trapezoidal form } \\
\text { less than } 500000 \mathrm{~mm}^{\wedge} 2\end{array}$ & $\begin{array}{l}700000 \\
\mathrm{~mm}^{\wedge} \mathbf{2}\end{array}$ & & & & & \\
\hline & & The width of the rear part of the Frame shall be less than $300 \mathrm{~mm}$ & $500 \mathrm{~mm}$ & & & & & \\
\hline & & $\begin{array}{l}\text { The plan (upper) area of the Engine Hood shall be of a trapezoidal form } \\
\text { less than } 500000 \mathrm{~mm}^{\wedge} 2\end{array}$ & & $\begin{array}{c}663765 \\
m m^{\wedge} 2\end{array}$ & & & & \\
\hline & & The width of the rear part of the Engine Hood shall be less than $300 \mathrm{~mm}$ & & $500 \mathrm{~mm}$ & & & & \\
\hline & & The luminous efficacy of the lights shall be more than 80 lumens / Watt & & & \begin{tabular}{c|c|}
60 \\
Iumens/w
\end{tabular} & & & \\
\hline & & One light shall point on the compaction point and the drumshell & & & No & & & \\
\hline & & The rear part of the drum shall be of $700 \mathrm{~mm}$ & & & & & $1000 \mathrm{~mm}$ & \\
\hline & & $\begin{array}{l}\text { A camera shall be installed pointing to the drum edge and the compaction } \\
\text { point }\end{array}$ & & & & & & YES \\
\hline & & The cameras shall not impede the movement in operation & & & & & & No \\
\hline
\end{tabular}

(b)

\begin{tabular}{|c|c|c|c|c|c|c|c|c|}
\hline \\
\hline Customer statements & $\begin{array}{l}\text { Value } \\
\text { dimension }\end{array}$ & Value Drivers & 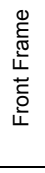 & 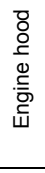 & 蒙 & $\begin{array}{l}\frac{\infty}{0} \\
\frac{0}{0} \\
\frac{\pi}{4} \\
\omega\end{array}$ & 气ે & 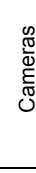 \\
\hline Increase productivity & $\begin{array}{l}\text { Compaction } \\
\text { capacity }\end{array}$ & Square meters compacted & 8 & & & & 5 & \\
\hline Increase compaction quality & $\begin{array}{l}\text { Compaction } \\
\text { quality }\end{array}$ & Quality of compacted asphalt & 3 & & & & 9 & \\
\hline \multirow{3}{*}{ Reduce operational inefficiencies } & \multirow{3}{*}{$\begin{array}{l}\text { Operational } \\
\text { Efficiency }\end{array}$} & $\begin{array}{l}\text { Visibility of drumshell \& compaction } \\
\text { point }\end{array}$ & 9 & 7 & 5 & & & $\mathbf{9}$ \\
\hline & & $\begin{array}{l}\text { Visibility of sorroundings during day } \\
\& \text { night }\end{array}$ & & 9 & 6 & & & \\
\hline & & Manoeuvrability & 8 & & & & 5 & 2 \\
\hline
\end{tabular}

In the 'value model' provided to three teams (Table 2-b displays an excerpt), the initial customer statements where translated into machine-level 'value dimensions' following a 1:1 correlation. These dimensions were cascaded down to 16 'value drivers', related to operational performances (e.g. square meter compacted) operational efficiency (e.g. manoeuvrability, visibility during day and night), changes in infrastructure (e.g. adaptability to future developments) and intangible values (e.g. brand acknowledgement, environmental impact).

The value contribution of the 'current frame and drum' was assessed by the authors taking the 'old frame and drum' as baseline, using a one to nine scale. A score between six and nine meant that the current design was found to be more value adding than the baseline. A score between one and four meant it was less value adding. A score of five meant that no difference was found between the two. 
Notably, both assessment reports (requirements checklist and value model) gave information about design trade-offs. This means that the improvement of one design property (e.g. the weight of the frame) would lead to worsening other properties in the model.

\subsubsection{Hypotheses development and method applied for data analysis}

The objective of the experiment was to study how a group of designers use a value model, in order to gain insights about the characteristics that promote the use of value models as coordinative artefacts (or boundary objects) in early design.

The first hypothesis was formulated based on the fact that requirements lists have been identified as useful boundary objects to specify the design assignment (defining the problem space) (e.g., Brace et al., 2010). Hence, to be a more effective boundary object, this hypothesis needs to be verified:

H1: To be a more effective coordinative artefact (or boundary object) than requirement checklists, the use of value models emphasizes more the activities related to the clarification of the problem domain and needs.

Hypothesis $H 1$ was tested by coding and analysing the experiments with the use of protocol analysis (PA, Gero and McNeill 1998). PA extends the 'think aloud' method through the use of a coding scheme based on generic models of design. Using PA it was possible for the authors to capture the designers' behaviour as a sequence of activities, and quantify their recurrence on a temporal basis (Gero \& Mc Neill, 1998; Ensici et al., 2013). The analysis featured an adapted version of the coding scheme proposed by Gero \& McNeill (1998) with some adjustments to avoid inconsistency and mitigate risk of misinterpretation. An additional strategy named "Preparing Documentation" was added to the original formulation to stress the difference between 'mere' physical actions with conceptual cognitive actions (Suwa et al., 1998). This strategy was detailed in three micro strategies: Making depictions, Look at own depictions, Making annotations (Suwa et al., 1998). Also, the authors added Analysing previous evaluation and Analysing previous representations were added by the authors to distinguish between the use of a requirement list or a value model and the use of the provided CAD-models. The decision to use such an elaborated coding scheme was driven by the necessity not only to focus on how the design teams made use of valuerelated information, but also to allow the identification of emerging secondary effects that a more or less intensive use of such information might have caused. Table 3 shows the final coding scheme.

In order to minimize biases, the researchers did not reveal to the participants the real objective of the study and did not share any information about the decision support tools received by different teams. The researchers were also not in the room during the design session but analysed the transcripts afterwards. During the experiments no guidelines for conversation were provided, and the participants were allowed to freely interact and interrupt each other. The segmentation of the protocol was first done individually by one encoder and later discussed with a second encoder to allow the arbitration needed to grant segmentation objectivity. The discussion targeted mainly 
the division of long sentences into two or more segments on the basis on designers' intentions (Bertoni, 2013).

Table 3: Micro strategies and their categories adopted for the study.

\begin{tabular}{|c|c|}
\hline Name & Code \\
\hline Analysing Problem & $\mathbf{A}$ \\
\hline Analysing a problem & AP \\
\hline Questioning a problem & AQ \\
\hline Justifying a problem & AJ \\
\hline Agreeing to a problem & AA \\
\hline Disagreeing a problem & $\mathrm{AD}$ \\
\hline Evaluating a problem & $\mathrm{AE}$ \\
\hline Analysing previous evaluation & AAE \\
\hline Analysing previous representations & $\mathrm{AAC}$ \\
\hline Proposing a Solution & $\mathbf{S}$ \\
\hline Proposing a Solution & SP \\
\hline Clarifying a proposed Solution & $\mathrm{SC}$ \\
\hline Retracting a previous solution & SR \\
\hline Making a design decision & SM \\
\hline Postponing a design action & SPO \\
\hline Looking ahead & SLA \\
\hline Looking back & SLB \\
\hline Analysing Solution & $\mathbf{Z}$ \\
\hline Analysing a Proposed Solution & $\mathrm{ZA}$ \\
\hline Justifying a proposed solution & $\mathrm{ZJ}$ \\
\hline Justifying a proposed solution through previous evaluation & ZJE \\
\hline Calculation on a proposed solution & $\mathrm{ZC}$ \\
\hline Postponing an analysis of action & $\mathrm{ZP}$ \\
\hline Evaluating a proposed solution & $\mathrm{ZE}$ \\
\hline Explicit Strategies & $\mathbf{E}$ \\
\hline Referring to Application Knowledge & EA \\
\hline Referring to Domain Knowledge & EK \\
\hline Referring to Design Strategy & ES \\
\hline Preparing Documentation & $\mathbf{P}$ \\
\hline Making depictions & PS \\
\hline Look at own depictions & PL \\
\hline Making annotations & PM \\
\hline
\end{tabular}

The second hypothesis started from the premise that literature has emphasized how effective boundary objects facilitate collective discussions in design teams (e.g.; Carlile, 2002). Starting with this premise, the second hypothesis was formulated:

H2: A value model is a more effective boundary object compared to a requirement list, because they facilitate collective discussions in design teams.

Hypothesis $H 2$ was tested by analysing the experiments adopting an observation approach (Anderson 1997, Larsson 2003), because observational approaches (Anderson, 1997) are the most applied methods for the analysis of successful boundary objects (e.g., Carlile, 2002; Larsson, 2003). To apply the observation approach, the authors cross-analysed the transcripts and the video recordings made during the sessions, adopting a pattern-matching logic (Yin, 2013; p.16). In this technique, the researcher establishes a pattern of expected findings, and then compares the empirical patterns derived from the data to this pre-determined pattern. These patterns were defined based on studies about effective objects for cross-functional collaboration (e.g., Carlile 2002; Larsson 2003). The author then proceeded to match the patterns derived from the transcripts using this pre-determined pattern. 
Table 4: Patterns of expected findings applied to assess H2.

\begin{tabular}{|c|c|c|}
\hline Pattern Name & Code & Expected finding \\
\hline Efficacy of trade-off identification & EFF-ID & $\begin{array}{l}\text { A more effective boundary objects reduces the } \\
\text { duration of trade-off identification (i.e., how early in } \\
\text { the design process trade-offs are identified) (Iorio \& } \\
\text { Taylor, 2014). }\end{array}$ \\
\hline Efficacy of trade-off resolution & EFF-RES & $\begin{array}{l}\text { A more effective boundary objects reduces the } \\
\text { duration of trade-off resolution (Iorio \& Taylor, } \\
\text { 2014). }\end{array}$ \\
\hline Boundary objects in time & BO-TIME & $\begin{array}{l}\text { A more effective boundary object can actively be } \\
\text { manipulated by the various participants during the } \\
\text { design process (Boujut and Blanco, 2003), especially } \\
\text { by those who work in the downstream activities } \\
\text { (manufacturing or service). As a consequence, the } \\
\text { mentioned boundary object connects one design effort } \\
\text { to the next, serving as a boundary object in time. }\end{array}$ \\
\hline Manage complexity & $\mathrm{BO}-\mathrm{CO}$ & $\begin{array}{l}\text { A more effective boundary object manages } \\
\text { complexity by reducing the instantaneous cognitive } \\
\text { load during decision-making (Richards et al., 2007). }\end{array}$ \\
\hline Applicability & BO-APP & $\begin{array}{l}\text { A more ffective boundary object can be applicable to } \\
\text { different trade-off situations. This definition is closely } \\
\text { connected to the definition of boundary objects } \\
\text { provided by Eckert et al. (2001): 'Objects that can be } \\
\text { read differently by people with different concerns and } \\
\text { expertise'. }\end{array}$ \\
\hline
\end{tabular}

The patterns, their definitions and references used are described in Table 4.

\section{Descriptive study findings: value awareness and coordination in design}

\subsection{Tracking and communicating 'intent' in design}

The empirical study confirms previous literature findings showing that the main goal for engineering designers is often to develop solutions as much as possible 'requirements-compliant'. This means that a solution concept is considered satisfactory if, for instance, performance, weight, specific fuel consumption, or reliability thresholds are met. Even though requirements often represent the only reference for early stage decision making, the descriptive study pointed to several areas of improvement for the requirement cascading process.

In aerospace applications, for instance, it is common practice to subcontract design tasks to manufacturers with highly specialized expertise. A first problem with subsystem manufacturers is that the initial contractual requirements cascaded down from system integrators are indicative at best. Furthermore, when requirements from the level above are interpreted and used to generate more requirements for the sub-system, there is often a lack of awareness of the original design intent due intrinsic information loss in the decomposition process.

Even for system integrators, as reported by a Project Manager working in Company A, there is a notion of "lost in translation" in the process of interpreting and translating 
the initial needs into a set of specifications for the solution that are relevant for other functions to work with:

"We have had difficulties in having the marketing department writing the need, so the real customer need, the underlying need [...] instead [...] they write requirements. And we believe in them, of course, but one does not know anyway exactly what the need is."

A major concern today is that the task of defining requirements from the initial expectations is often performed by dedicated functions with limited engineering involvement. The risk in doing this is that possible trade-offs between product properties and lifecycle values cannot be fully identified due to the 'noise' that inevitably characterise the translation process:

"If you get the real customer need, then you can work on a technical solution that maybe is not at all the one that the market department had written at the beginning in the requirements list."

At the same time, the dynamic business landscape is an issue too: sub-systems and components may feature long development lead times, which means that customer preferences and values may change over time. The quote below, which belongs to a respondent at Company $\mathrm{B}$, summarises both the issue related to the evolution of customer preferences over time, and the problem of interpreting these correctly (i.e., "changing the stories") during each target cascading process step:

"It's not always the case that we are aiming for the right things, because the priorities and the stories are changing when you have so many steps in between the market and the development."

All the quotes above points to the same phenomenon: when design activities are cascaded down from macro (system) to micro level (sub-systems and components), contextual information is rarely communicated. The lack of first-hand information about why a requirement looks like it does (i.e., its rationale), exposes the design team to the risk of targeting local optimal solutions, not more 'global' ones (i.e, the resulting design is sub-optimal). Lacking a 'sound basis' for decision-making, engineers avoid opening up the design space, but rather follow their traditional 'modus operandi', which often means down prioritising radical designs in favour of more incremental solutions. Different people see different realities from similar data, interpreting them differently. Adding filters between the collected customer needs and the developed product skews the understanding of what the customer actually values.

"It's a long chain from customer to designer [...] and we can shorten this chain very powerfully if we have a way of working also."

A great portion of stakeholders' needs and values remain 'floating' and are not captured as design requirements in the preliminary design stages. This is particularly relevant for downstream lifecycle properties - often labelled as non-functional requirements of 
"ilities" (McManus et al., 2007) - such as maintainability and sustainability. While some aspects of sustainability are partially encompassed by the established drivers for design (e.g., specific fuel consumption, lifetime and weight reduction in the automotive and aerospace industry), others are less readily quantifiable (e.g., material criticality from an availability and socio-ecological sustainability perspective) and problematic to use as drivers for development. Identifying these floating targets, sharing them within and across the company, and relating them to characteristics for the product is critical to achieve a shared understanding of value between the engineering design team participants. The interviews highlight the need to complement requirements checklists with descriptions able to bring on the engineers' table the original intent of a design, and the context in which requirements originates. As highlighted by respondents at Company $\mathrm{B}$, design intent is best captured by a prioritized list of needs from the customers (as well as by all relevant stakeholders), and by information about market, business process and value chain:

"The biggest problem we have had within our organization is that it is really crucial that you understand the customer process, the chain from the market, then the customer all the way to us. It is global and it is very long, and every part of the chain has different priorities [...]".

Finding 1: Coordinating artefacts for conceptual design shall emphasise traceability and transparency of the initial set of needs. This can be achieved by artefacts that are able to capture and communicate the context and underlying intent of the design requirements across functions and teams.

\subsection{Constructing 'plastic' and 'lightweight' coordinative models}

The study at company B illustrates the necessity of challenging the understanding of what customers value, and how this relates to design solutions. Challenging the design requirements by asking continuous "why?" is considered vital to improve the list of specifications of a solution.

"To me the biggest benefit is that we from the engineering department, get a much stronger understanding about what is lying behind the requirements we get from our marketing department. [...] So, theoretically we can gain a lot by understanding it. Why, why... not just to accept it."

For instance, it is intuitive to relate how weight reduction for a machine and its components impact reduced fuel consumption. However, it is more difficult to understand how reducing weight may impact aspects such as, brand, image, serviceability, and production line commonality.

Company $\mathrm{C}$ further highlighted that, at the time of making design decisions for an aeroengine, dimensions such as weight, purchase price, fuel burn, etc. must be traded-off with softer value aspects, such as, sustainability or usability. These latter are not discussed exclusively in design but must rather be questioned with regards to more traditional functional and performance-related aspects: 
"If you do not have a trade factor between two things, then it is my experience that where you have a number on, it wins... If we cannot set a quantitative measurement for something during conceptual design, it sinks down simply. When we talk about qualitative measurements; there is a tendency to ignore them."

The different object worlds (Bucciarelli, 2002) of the professionals involved in the cross-functional team shall then be synthetized and aggregated in a single model for 'value'. This kind of intervention is fundamental for the negotiation of the design space, because team members - using the model to synthetize their beliefs and questioning what they see - can create new knowledge and increase awareness.

"The requirements are very strict and are measurable, but sometimes value is much more about discussion and communication"

Hence the single-model approach is seen as an enabler for people to gather around, voice their different perspectives and concerns, and take appropriate actions. At the same time, it is intended to preserve efficiency of the process, avoiding the risk of speculation, or 'off-topic' discussions in the decision meeting (Kleinsmann et al., 2012). Yet, marketing or service managers might not have sufficient technical background to know how detailed engineering properties impact long-term value creation. Conversely, engineers lack of financial, marketing, or sustainability insights to know how technical characteristics in their domain impact needs and expectations. For this reason, the chosen 'model' shall be 'plastic' enough so that every member of the team to visualize the design problem from their points of view. At the same time, it shall be 'lightweight' enough and to enable confrontation. Since the purpose is that to work as common denominator for the cross-functional team, the 'value model' shall be constructed in such a way that it can be understood and operated independently from the specific knowledge of each involved individual.

Finding 2: Effective coordinating artefacts for conceptual design shall be model-based, because the members of a cross-functional team are used to 'model' problems to generate the necessary information for decisions. These artefacts shall be 'plastic' enough to adapt to different roles and disciplines and shall be 'lightweight' enough to be understood and operated at different levels of the value chain, from customers to sub-contractors.

Literature (e.g. Isaksson et al., 2009) recognizes the importance of models as a means for verification, but stresses also the need for a broader view on how models are used to support new product development, i.e., utilizing models to guide on what to develop rather than focusing if the product does not fail regarding performance. This focus on innovation and models has resulted in a plethora of multi-domain models (Bertoni et al., 2016), which however still leaves designers with the challenge of making thoughtful trade-off decisions between conflicting attributes (Isaksson et al., 2013). While the idea of aggregating all these multidisciplinary models in a 'value model', a 'one size fits all' strategy may not be feasible. There is a need to increase the understanding of how practitioners belonging to different disciplines use model-based supports in practice to make the case for a particular design goal. 
The investigation of the role of value models as boundary objects in design is a matter of pointing to "how subtly, fluently and effortlessly designers negotiate common ground" (Larsson 2003 p.156). Although this type of evaluation may be challenging (Carlile 2002), literature points to the necessity of testing and investigating the role of objects in facilitating collaborative work in design (Bucciarelli 2002). This need for testing is also stressed by researchers involved in the development of value driven approaches (Soban et al. 2011). Soban et al. (2011) propose that value is the most intuitive criteria to improve decision-making in design, mainly because, in the words of Hazelrigg (1988) "values tell engineers what you want. Requirements only tell them what you don't want". Building on this assert, value as decision criteria is intended to change the designers' cognitive behaviour, compared to the use of requirements. These hypotheses would require testing and evaluation activities, alongside the development of design supports (Collopy 2012). For this reason, this study has included experimental activities (video and audio recorded) in order to gather and analyse data about the effectiveness of using a semi-quantitative value model as boundary object. Experiments with students in design sessions were organised to evaluate the designers' behaviour when using such models, in comparison to requirement checklists. The focus of this study was to evaluate the differences in the designers' behaviours when using a modelbased representation for value compared to the use of a requirement-based representation.

\section{Results from the experimental activities: protocol analysis}

The sessions were transcribed and separately coded by three encoders. The final version of the coding was obtained by the comparison of the three protocols and by discussing the non-aligned judgments.

Initially, the authors analysed how the macro-strategies were impacted by the adoption of the value assessment report. Figure 2 shows (bold continuous line) that the teams using value reports spent on average $8 \%$ more time analysing the problem compared to the teams using the requirements checklist. This may indicate that these teams had more thoughtful discussion of the problem statement. Figure 2 also highlight significative differences in Standard Deviation (SD) across the different macro strategies, likely indicating that the team supported by value assessment report were able to follow a more repeatable, and likely consistent, process. 


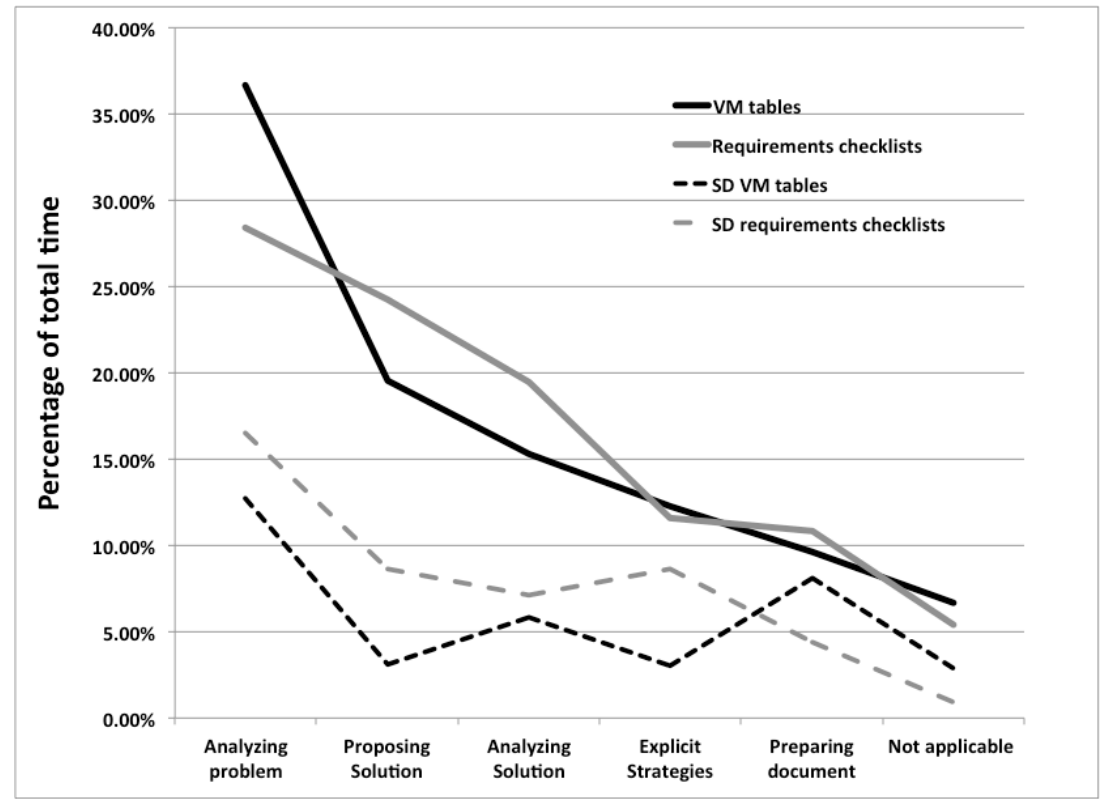

Figure 2: Results from the analysis of macro-strategies: time segmentation.

Figure 3 summarizes the percentage of time spent on each micro strategy (filtering out those discussed less than $1 \%$ of the time).

Several trends are noticeable; compared with their counterpart, the teams using the value assessment report:

- Have spent significantly more time on the analysing previous evaluation micro strategy (about 7\%) and also more time (about 3\% in absolute terms) using the assessment report to justify proposed solutions.

- Have spent more time on referring to design strategies (about 4\%).

In turn, the teams using the requirements-based report have spent more time on clarifying a solution (about 4\%) than the team using a value report. These teams showed a tendency of 'jumping into' solution earlier and spend more time on the clarification and analysis of the detailed technical characteristics of the solutions, then going back to the problem statement, and referring to own application knowledge to reformulate a new solution. 


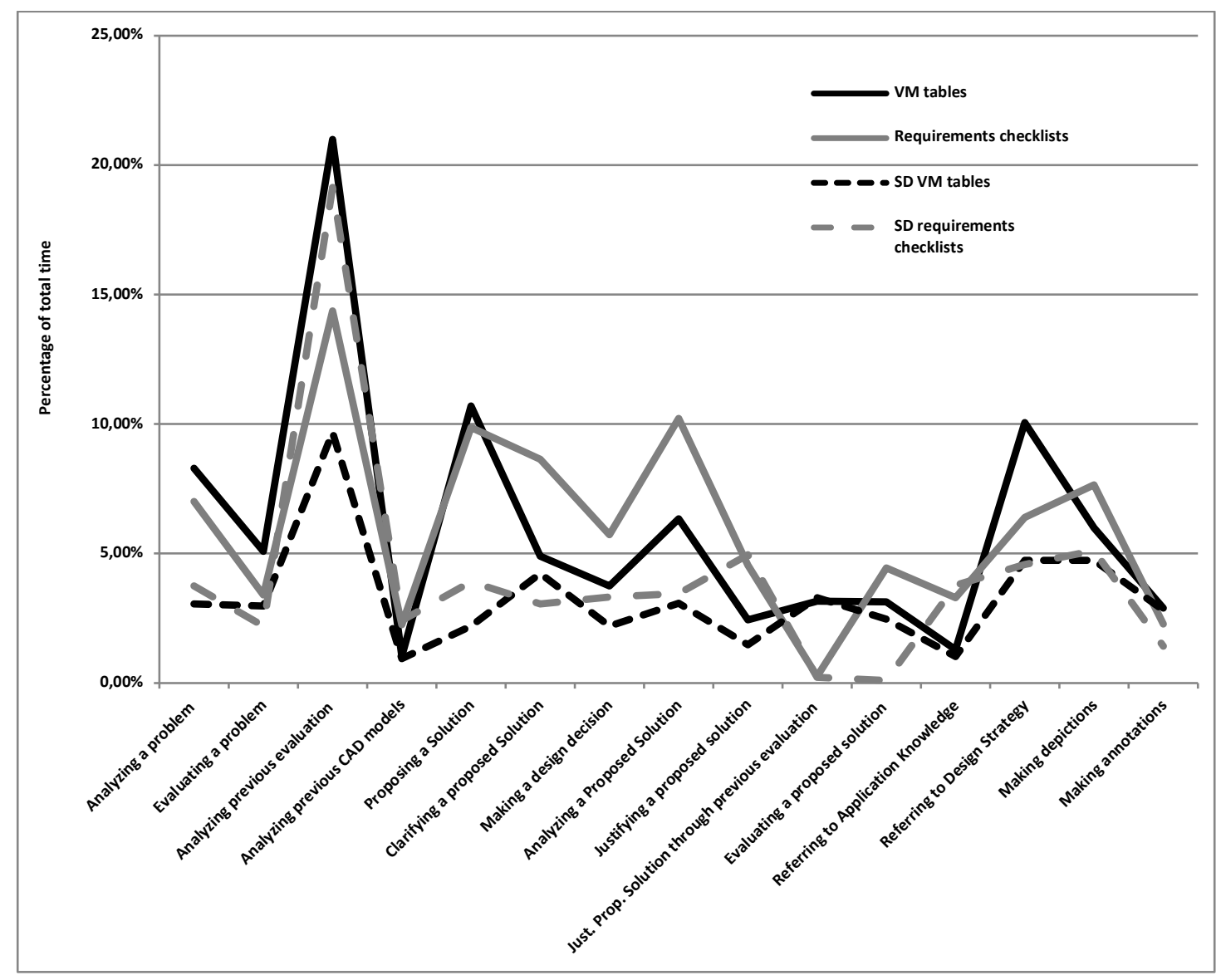

Figure 3: Results from the analysis of micro strategies: time segmentation.

It is also noticeable that the teams using the value assessment report have a more uniform distribution of time spent on assessing the report (exactly: 10.6\%, 29.8\%, $22.6 \%$ ), while for their counterparts this micro strategy feature a more variable distribution $(36.3 \%, 0.97 \%, 5.9 \%)$. This observation was the main input for the observations reported in section 5.1.2.

Observing the time spent on the assessment report in relation to the average time spent analysing problems, a change in the design team's behaviour can be observed. The value assessment report teams have spent about $58 \%$ of the time spent for problem analysis dealing with the analysis of the value report, while the teams using the requirements checklists have spent half of their time on the same activity.

\subsubsection{Results from the questionnaire}

The results from the protocol analysis were complemented by an individual questionnaire to collect the participant's self-assessment of the design sessions. The respondents were asked to indicate their agreement to 11 questions covering 2 main topics (their behaviour during the design session and the use of provided material - the requirements checklist and value report).

Even if the qualitative results cannot be considered statistically relevant due to the limited size of the sample, they had a triangulation purpose and reinforce some of the 
patterns recognized in the previous section. Figure 4 provides further evidence that the teams using the value assessment report spent more time on analysing the problem, while those using requirements as input spent more time on proposing and clarifying solutions. At the same time, the teams using the requirements checklist perceived to have focused more on the engineering characteristics of the new solutions, rather than on discussing design trade-offs like the teams working with the value assessment report. Overall, the latter was also perceived as a more useful support for this process than the requirement checklists.

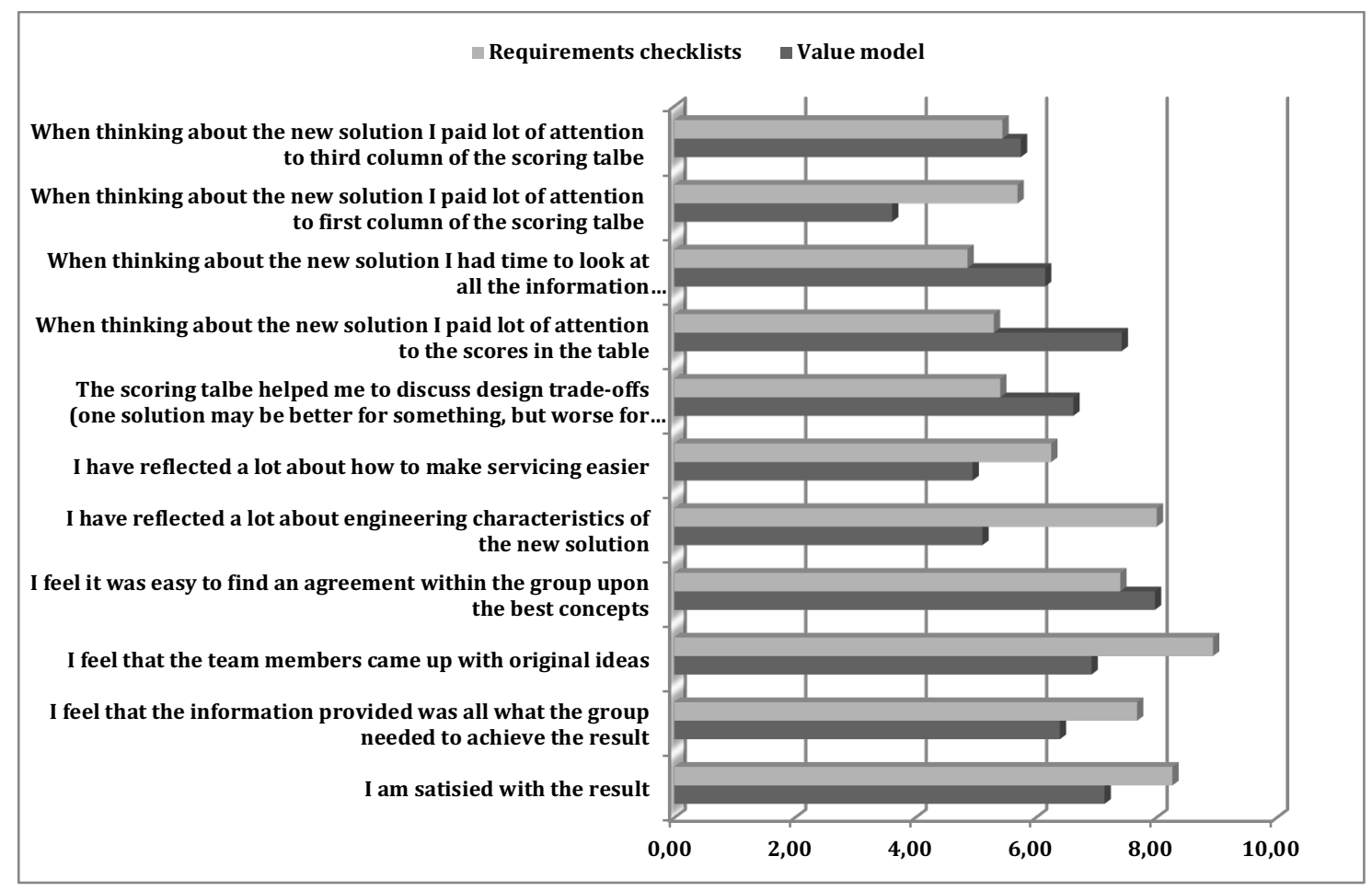

Figure 4: Results from the questionnaires.

\subsubsection{Results from the observation study}

This section targets $\mathrm{H} 2$ and highlights the role of the value model report in facilitating cross-boundary discussions in conceptual design. It features three excerpt transcripts from the design experiments, which were selected by the authors to illustrate and exemplify: 1) how the value assessment report works as a boundary object for conceptual design, and 2) in what way it is more effective compared with the requirement-based assessment report.

\section{Role of the assessment report as boundary object: making sense of "visibility" and "manoeuvrability"}

In this situation, the team is in the $2^{\text {nd }}$ minute of the experiment. Three students are analysing the information contained in value report to figure out possible areas of improvement for the system. 


\section{Transcript \#1: Visibility and manoeuvrability}

S\#3: “...this one got good results on everything" [moving the pen along the entire "visibility of drum shell and compaction" point row]

S\#2: "visibility of surroundings during day and night [pointing to the respective value driver in the report] ... yeah, because the lights are bigger, and better [looking at CADmodel] ..."

S\#3: "but how can the camera be worse here? [pointing to score in the report]"

S\#1: "but what does it affect? Ah, manoeuvrability..." [pointing to score between "camera" and "manoeuvrability"]

S\#2: "it should be better..."

S\#1: "but maybe it is in the way... if there is a pole or something like that... [gesturing] yeah, it is sticking out of it [pointing at the camera in the CAD-model] ..."

S\#3: "so maybe it will be better to have the camera here, between the lights [pointing to the centre of the frame in the CAD-model]"

S\#2: "Yes, but then you do not see this [pointing to drum shell edge on the CAD-model] ... they want to see this..."

S\#3: "that's true, but the camera is always there, if there is a pole or something like that..."

The story above concerns the installation of a camera which is problematic for the operators of the machine because it may collide with an obstacle while in operation. $S \# 3$ proposes to place the camera in the front of the frame, but $S \# 2$ raise her concern for this choice having a negative impact on the visibility of the drum shell and compaction point. Interestingly, she is pointing to the same value driver highlighted by $S \# 3$ at the beginning of the transcript, who stated the value driver "having good results on everything". $S \# 2$ seems to follow the same line of thoughts: she does not want to move the camera from the current position, since it is pointed to the drum shell and compaction point. However, $S \# 3$ raises her concern about the cameras having a negative impact in operation. Interestingly, she uses the same story about the pole told by $S \# 1$.

Notably, the three students use different part of the report for different purposes. $S \# 2$ uses the report to assess the "goodness" of the lights in providing "visibility during day and night". $S \# 3$ use the score in the report to voice her concern about the camera. S\#1 connects this score to the correspondent value driver and tells a story about what he thinks is the reason why the camera has a negative impact on manoeuvrability. The pole "in the way" seems to be a commonly agreed story (Larsson, 2003) to explain to other team members the reason why the cameras have a negative impact on manoeuvrability.

\section{Role of value model as effective boundary object: making sense of "easy to clean" and "wear resistance"}

In this situation, the team is in the second half of the design session. The team is brainstorming solutions for the frame and drum. For this purpose, the four students decided to split in two groups. In one group, $S \# 1$ and $S \# 4$ are analysing the value model and focus on the position of the camera in the current configuration. 


\section{Transcript \#2: Easy to clean and wear resistance}

S\#1: "what is bad with the camera? [pointing at table]"

S\#1: "So there is a problem with the cleaning... it is hard to clean the camera... and it's hard to maintain this [pointing at table] ... so it's also fragile... so changing these external cameras to internal cameras instead [pointing at CAD-model] ... when you can protect them by placing them inside... it could help..."

After 5 minutes, the two groups reconvene to discuss the generated solutions and how they could be integrated into a single concept. One member of the other group $(S \# 3)$ talks to $S \# 1$.

S\#3: "so if you have better ideas about the camera... that we can add..."

S\#1: "yeah! We just came up with the idea of internalizing the camera inside the hood instead of having it like... sticking out... because this part here [pointing at CAD] will make it very hard to clean and it's very fragile... and you cannot really steer because it points out"

S\#3: "Because the problem with the camera was [pointing at table] ...because of... why did you choose that? I mean... to solve which problem of this? [pointing at table?]"

S\#1: "The manoeuvrability [pointing to "manoeuvrability" in the "value drivers" column] ... the easy to clean ... this part [moves and points the pen to the "easy to clean" value driver] ... and this one, the wear resistance [points to the "wear resistance" value driver] ... so we just came up with an idea"

S\#3: "okay, then we focus on these [pointing at table]"

In this sequence, two members of the team used the information contained in the value model for different purposes. $S \# 1$ uses the value model to assess the design problem and to generate a solution. When $S \# 3$ asks about the reason for the solution of having the cameras inside the engine hood, $S \# 1$ uses a verbal explanation, and makes reference to the CAD-model. However, $S \# 3$ does not seem to have fully understood this verbal explanation. In order to anchor this understanding to be able to assess the contribution of the solution, $S \# 3$ uses the value model to inquiry $S \# 1$ 's decision. The reference to the value model triggers $S \# 1$ to further explain his choice. Interestingly, S\#1 does not use own words but makes reference in a single sentence to three value drivers present in the table (manoeuvrability, easy to clean, wear resistance). The value drivers seem to function as a shared vocabulary between the two students, who eventually find agreement at the end of the transcript. The use of a shared vocabulary is one of the advocated features of effective boundary objects (Carlile, 2002). Providing "similarities in voice" among team members is of particular importance when team members come from different disciplines and backgrounds (Larsson, 2003).

\section{Comparison with requirements checklist: "engine hood"}

In this situation, a team using a requirements checklist is at the $19^{\text {th }}$ minute. The team analyses the requirements for the engine hood to find areas for improvement. $S \# 3$ analyses the report and finds the requirement "the upper area of the engine hood shall be less than 500.000 square millimetres". 


\section{Transcript \#3: Engine hood}

S\#2: How about the engine hood? I think a lot can be improved there..."

S\#3: "let's see the engine hood [analysing the table]... maybe it is this shape [pointing to upper area of the engine hood in the CAD-model]... so the area and also the weight... it should not weight more than 100 kilos, and now it is 130 [pointing at table]"

S\#2: "But could we do something with this shape here... to weigh less? But do we want a bigger area?"

S\#3: "no, less area, because this is now 700.000 square millimetres..."

S\#1: "so we could have like this curve even more down here [pointing with a pen on the CAD-model, extending the current profile of the engine hood]"

While $S \# 1$ is clarifying to $S \# 3$ his idea, $S \# 2$ is analysing the report. She raises a concern about the solution described by $S \# 1$, by highlighting another requirement in the table.

S\#2: "But as you said, if we do like this curve [mimics the same change in the profile of the engine hood in the CAD-model], we have less volume... because we have decreased the volume also... and it has to be more than 0.8 cubic meters, and now it is 0.6... [pointing at requirements checklist]"

S\#1: "oh, yeah, that's a problem..."

In this specific situation in the transcript, the team leaves the conversation about the engine hood and goes on focusing on analysing the drum. The requirements checklist serves as boundary object; as different members use it to raise their different concerns. However, the requirements checklist helped to identify trade-offs, but did not help the team to effectively solve them. The information contained in the assessment report should have aided the team by highlighting the value contributions that the different requirements had on the customer operational process, to collectively discuss what the customer would have valued most between the different attributes and to solve the conflict. Studies on negotiations and trade-offs describe how designers must first identify and agree that a negotiation (or trade-off) is, in fact, required. This trade-off identification stage can take time or might not occur at all (Iorio \& Taylor, 2014). If designers agree that a trade-off is required, they need to engage in developing a strategy for leveling such incompatibility. This trade-off resolution stage (Iorio \& Taylor, 2014) can take time, and delays negatively impact the decision-making process (Carlile 2002; p. 541). This transcript highlights how, while the requirements checklists aided the team to reduce the time of trade-off identification, it did not support the trade-off resolution stage as it is observed for a team using the value model.

\section{Discussion}

The notion of value models is traditionally associated with the use of a unique monetary objective function to encourage design optimization and eliminating those constraints that have been expressed as performance requirements (Collopy \& Hollingsworth, 
2011). Noticeably, value models have been considered, so far, as a fundamentally disciplinary tool, being created by engineers and for engineer to address various forms of uncertainty in making engineering design decisions (Soban et al., 2011). Their usage outside the engineering environment has historically being limited, mainly because value models are often perceived as a 'black box' into which data is entered, and then a result is generated (Bertoni et al., 2018).

The results presented in this paper highlight how the uptake of servitization, and the need to include more intangible objectives into design decision making - such as sustainability and customer satisfaction - implies a deep transformation of the "value model' concept. Not only this shall support objective and repeatable decisions but shall also be transparent enough to make possible for different functional expertise to work toward a common goal.

One tangible effect of using value models to foster cross-boundary discussions in design relates to the increased ability of systematically represent environmental- and sustainability-related targets in the requirement description for a system. While some aspects of sustainability are partially encompassed by the established drivers for design (e.g., specific fuel consumption, lifetime and weight reduction in the automotive and aerospace industry), others are less readily quantifiable (e.g., material criticality from an availability and socio-ecological sustainability perspective) and problematic to use as drivers for development. Value models are used then to raise awareness on sustainability as a value-creating factor for the company. Creating a proxy for 'value' through the use of different modelling techniques - raises awareness among the team of how a sustainable design choice can create value for customers and stakeholders and, hence, generate market success in the long term. In a nutshell, value models, by gathering knowledge form different disciplinary areas of the enterprise, make possible for the design team to balance sustainability requirements with economic interests since a preliminary design phase.

\subsection{Limitation of the study}

This study presents a number of limitations. The use of semi-structured interviews requires to tap the memories of the decision makers, which can cause issues in distortion and memory failure (Mintzberg et al. 1976). The authors attempted to mitigate distortion by conducting multiple interviews, across a heterogeneous mix of individuals.

With regards to the experimental activities, the authors believe that the results can be trustworthy, in spite of the limited set of data and the limitation of the method (Cross et al., 1996). On the one hand, protocol analysis is recognized as a proven approach, and the method has been applied even with a small number of experiments (e.g., Kan $\&$ Gero, 2008). On the other hand, although the observation of design teams in a real working scenario would be preferable, the sample - designers at the last year of Master in three different engineering programs - is considered relevant for the purpose of the study. Master students are advanced beginners (Kleinsmann et al., 2012), who understand how to design and take situational factors into account.

Yet, the design sessions were conducted in an artificial setting, which is with students in a university environment and not with practitioners in a real industrial environment, and this represents a limitation to the generalization of the results. Nevertheless, 
literature shows that a big part of the research experiments testing new tools and methods are still conducted in artificial settings (Ellis \& Dix, 2006). Master students can be considered the target population for the development of new methods and tools, as they are soon becoming novice engineers in industry exposed to similar boundary conditions (intensity of teamwork, limitations in the knowledge baseline, deadlines) and problem statements (Bertoni, 2013).

\section{Conclusions}

The present study has reviewed the use of value models as possible decision support in the early design stages. With regards to the question: What are the characteristics that promote the use of value models as coordinative artefacts (or boundary objects) in early design? The results of this paper highlight how the uptake of servitization, and the need to include more intangible objectives into design decision making - such as sustainability and customer satisfaction - implies a deep transformation of the "value model' concept. Not only this shall support objective and repeatable decisions but shall also be transparent enough to make possible for different functional expertise to work toward a common goal. By experimenting the use of a prototypical value model in design sessions with master students, the paper provides further insight into the mechanisms triggered by a coordinative artefact in conceptual design. The results from the protocol analysis support the hypothesis that the use of value models emphasizes more the activities related to the clarification of the problem domain and needs. The results of the observation study highlight that, while requirement checklists facilitate the collective identification of trade-offs and functional/physical trade-offs, the value assessment report triggers a different kind of negotiation among the team. This is centred on what the customers may prefer between different product properties by looking at their solution-independent context, likening the features for 'boundary objects' featured in literature.

Future research will address the challenge of integrating value-based decision support in the ecosystem of tools that exist in today's engineering organizations. It will also aim to apply value models in more data-rich situations, as well to improve the visualization of modelling results.

\section{References}

Anderson, R. J. 1997. Work, Ethnography and System Design. In Encyclopedia of Microcomputing. Vol. 20. pp. 159-183.

Baines, T.S., Lightfoot, H.W., Evans, S., Neely, A., Greenough, R., Peppard, J., Roy, R., Shehab, E., Braganza, A., Tiwari, A., (2007) State-of-the-Art in Product-Service Systems. Journal of Engineering Manufacture, 221 (10), 1543-52.

Becattini, N., \& Cascini, G. (2014). General-purpose requirements checklist for improving the completeness of a design specification. In DS 77: Proceedings of the DESIGN 2014 13th International Design Conference (pp. 111-120).

Bertoni, A. (2013). Analyzing Product-Service Systems conceptual design: The effect of color-coded 3D representation. Design Studies, 34(6), 763-793.

Bertoni, M. and Bertoni, A. (2019) Iterative value models generation in engineering design: lessons learned from a cross-company study. Design Science, Vol.5, No. 18, doi: 10.1017/dsj.2019.1 
Bertoni, M., Bertoni, A., Isaksson, O., (2018) EVOKE: A Value-Driven Concept Selection Method for Early System Design. Journal of Systems Science and Systems Engineering 27(1), 46-77.

Bertoni, M., Panarotto, M., \& Larsson, T. C. (2016). Boundary objects for PSS design. Procedia CIRP, 47, 329-334.

Boujut, J. F., \& Blanco, E. (2003). Intermediary objects as a means to foster co-operation in engineering design. Computer Supported Cooperative Work (CSCW), 12(2), 205-219.

Brace, W., \& Thramboulidis, K. (2010). From requirements to design specifications-A formal approach. In DS 60: Proceedings of DESIGN 2010, the 11th International Design Conference, Dubrovnik, Croatia (pp. 639-650).

Browning, T. R. (2003). On customer value and improvement in product development processes. Systems Engineering, 6(1), 49-61.

Bucciarelli, Louis L. "Between thought and object in engineering design." Design studies 23.3 (2002): 219-231.

Carlile, P. R. (2002). A pragmatic view of knowledge and boundaries: Boundary objects in new product development. Organization science, 13(4), 442-455.

Cavalieri, S., \& Pezzotta, G. (2012). Product-Service Systems Engineering: State of the art and research challenges. Computers in Industry, 63(4), 278-288.

Charnley, F., Lemon, M., \& Evans, S. (2011). Exploring the process of whole system design. Design Studies, 32(2), 156-179.

Cheung, J., Scanlan, J., Wong, J., Forrester, J., Eres, H., Collopy, P., ... \& Briceno, S. (2012).

Application of value-driven design to commercial aeroengine systems. Journal of Aircraft, 49(3), 688702 .

Coley, F., \& Lemon, M. (2008). Supporting multiple stakeholders in the design of more sustainable and systemic solutions: the case of the sustainable sports car. Design Principles and Practises: An International Journal, 2(2), 27-34.

Coley, F., \& Lemon, M. (2008). Supporting multiple stakeholders in the design of more sustainable and systemic solutions: the case of the sustainable sports car. Design Principles and Practises: An International Journal, 2(2), 27-34.

Collopy, P. (2012, January). A research agenda for the coming renaissance in systems engineering. In American Institute of Aeronautics and Astronautics Symposium, Reston, VA (pp. 2012-0799).

Collopy, P. D., \& Hollingsworth, P. M. (2011). Value-driven design. Journal of Aircraft, 48(3), 749759.

Cross, N., Dorst, K., \& Christiaans, H. (Eds.). (1996). Analysing design activity. Wiley.

Durugbo, C. and Riedel, J.C.K.H. (2013). Viewpoint-participation-technique: A model of participative requirements elicitation, Concurrent Engineering: Research and Applications, 21(1): 3-12.

Eckert, C. (2001). The communication bottleneck in knitwear design: analysis and computing solutions. Computer Supported Cooperative Work (CSCW), 10(1), 29-74.

Ellis, G., \& Dix, A. (2006, May). An explorative analysis of user evaluation studies in information visualisation. In Proceedings of the 2006 AVI workshop on BEyond time and errors: novel evaluation methods for information visualization (pp. 1-7). ACM, Venice, Italy.

Ellis, G., \& Dix, A. (2006, May). An explorative analysis of user evaluation studies in information visualisation. In Proceedings of the 2006 AVI workshop on BEyond time and errors: novel evaluation methods for information visualization (pp. 1-7). ACM, Venice, Italy.

Ensici, A., Badke-Schaub, P., Bayazıt, N., \& Lauche, K. (2013). Used and rejected decisions in design teamwork. CoDesign, 9(2), 113-131. 
Eres, M. H., Bertoni, M., Kossmann, M., \& Scanlan, J. (2014). Mapping customer needs to engineering characteristics: an aerospace perspective for conceptual design. Journal of Engineering Design, 25(13), 64-87.

Fabrycky, W. J., \& Blanchard, B. S. (1991). Life-cycle cost and economic analysis. Prentice Hall.

Gero, J. S., \& Mc Neill, T. (1998). An approach to the analysis of design protocols. Design studies, 19(1), 21-61.

Grönroos, C., \& Voima, P. (2013). Critical service logic: making sense of value creation and cocreation. Journal of the Academy of Marketing Science, 41(2), 133-150.

Hallstedt, S. I., Bertoni, M., \& Isaksson, O. (2015). Assessing sustainability and value of manufacturing processes: a case in the aerospace industry. Journal of Cleaner Production, in press.

Hazelrigg, G. A. (1998). A framework for decision-based engineering design. Journal of mechanical design, 120(4), 653-658.

Imre, Ö. (2015). Learning by negotiation-Implementing a journal management system. In 12th European, Mediterranean and Middle Eastern Conference on Information Systems (EMCIS 2015), 1-2 June, 2015.

Iorio, J., \& Taylor, J. E. (2014). Boundary object efficacy: The mediating role of boundary objects on task conflict in global virtual project networks. International Journal of Project Management, 32(1), 7 17.

Isaksson, O., Kossmann, M., Bertoni, M., Eres, H., Monceaux, A., Bertoni, A., ... \& Zhang, X. (2013, June). Value-Driven Design-A methodology to Link Expectations to Technical Requirements in the Extended Enterprise. In INCOSE International Symposium (Vol. 23, No. 1, pp. 803-819).

Isaksson, O., Larsson, T. C., \& Rönnbäck, A. Ö. (2009). Development of product-service systems: challenges and opportunities for the manufacturing firm. Journal of Engineering Design, 20(4), 329348 .

Kan, J. W., \& Gero, J. S. (2008). Acquiring information from linkography in protocol studies of designing. Design Studies, 29(4), 315-337.

Kleinsmann, M., Deken, F., Dong, A., \& Lauche, K. (2012). Development of design collaboration skills. Journal of Engineering Design, 23(7), 485-506.

Krogstie, B. R., \& Divitini, M. (2007). Practice-based learning as mobile learning: the role of boundary objects. In IADIS International Conference in Mobile Learning.

Larsson, A. (2003, November). Making sense of collaboration: the challenge of thinking together in global design teams. In Proceedings of the 2003 international ACM SIGGROUP conference on Supporting group work (pp. 153-160). ACM.

Larsson, A. (2003, November). Making sense of collaboration: the challenge of thinking together in global design teams. In Proceedings of the 2003 international ACM SIGGROUP conference on Supporting group work (pp. 153-160). ACM.

Larsson, A., Ericson, Å., Larsson, T., Isaksson, O., \& Bertoni, M. (2010). Engineering 2.0: exploring lightweight technologies for the virtual enterprise. In From CSCW to Web 2.0: European Developments in Collaborative Design (pp. 173-191). Springer London.

Mc Neill, T., Gero, J. S., \& Warren, J. (1998). Understanding conceptual electronic design using protocol analysis. Research in Engineering Design, 10(3), 129-140.

McManus, H., Richards, M., Ross, A., \& Hastings, D. (2007, September). A Framework for Incorporating “ilities" in Tradespace Studies,". In AIAA Space (Vol. 1, pp. 941-954).

Miles, M. B., \& Huberman, A. M. (1994). Qualitative data analysis: An expanded sourcebook. Sage.

Mintzberg, H., Raisinghani, D., \& Theoret, A. (1976). The structure of" unstructured" decision processes. Administrative science quarterly, 246-275. 
Monceaux, A., \& Kossmann, M. (2012). Towards a Value-Driven Design Methodology-Enhancing Traditional Requirements Management Within the Extended Enterprise. In 22nd Annual INCOSE International Symposium. Rome, Italy.

Pahl, G., \& Beitz, W. (2013). Engineering design: a systematic approach. Springer Science \& Business Media.

Price, M., Soban, D., Mullen, C., Butterfield, J., \& Murphy, A. (2012). A novel method to enable tradeoffs across the whole product life of an aircraft using value driven design. Journal of Aerospace Operations, 1(4).

Price, M., Soban, D., Mullen, C., Butterfield, J., \& Murphy, A. (2012). A novel method to enable tradeoffs across the whole product life of an aircraft using value driven design. Journal of Aerospace Operations, 1(4).

Rahi Rasoulifar, Guillaume Thomann, François Villeneuve. Engineering Design in surgery: An analysis model for prototype validation. CIRP Design Conference 2008: Design Synthesis, Apr 2008, Twente, Netherlands. 6 p.

Raudberget, D., Levandowski, C., Isaksson, O., Kipouros, T., Johannesson, H., \& Clarkson, J. (2015). Modelling and assessing platform architectures in pre-embodiment phases through set-based evaluation and change propagation. Journal of Aerospace Operations, 3(3, 4), 203-221.

Ravald, A., \& Grönroos, C. (1996). The value concept and relationship marketing. European journal of marketing, 30(2), 19-30.

Richards, M. G., Shah, N. B., Hastings, D. E., \& Rhodes, D. H. (2007, June). Architecture Frameworks in System Design: Motivation, Theory, and Implementation. In INCOSE International Symposium (Vol. 17, No. 1, pp. 981-990).

Schmidt, K., Wagner, I. (2002). Coordinative artifacts in architectural practice. Fifth International Conference on the Design of Cooperative Systems (COOP 2002)/Cooperative Systems Design: A Challenge of the Mobility Age. Amsterdam, NL, IOS Press.

Schmidt, K., Wagner, I. (2002). Coordinative artifacts in architectural practice. Fifth International Conference on the Design of Cooperative Systems (COOP 2002)/Cooperative Systems Design: A Challenge of the Mobility Age. Amsterdam, NL, IOS Press.

Shimomura, Y., \& Arai, T. (2009). Service engineering-methods and tools for effective PSS development. In Introduction to Product/Service-System Design (pp. 113-135). Springer London.

Soban, D., Hollingsworth, P., \& Price, M. (2011, March). Defining a research agenda in Value Driven Design: Questions that need to be asked. In Air Transport and Operations-Proceedings of the Second International Air Transport and Operations Symposium 2011 (pp. 372-382).

Star, S. L., \& Griesemer, J. R. (1989). Institutional ecology,translations' and boundary objects: Amateurs and professionals in Berkeley's Museum of Vertebrate Zoology, 1907-39. Social studies of science, 19(3), 387-420.

Strauss, A. L., \& Corbin, J. M. (1990). Basics of qualitative research (Vol. 15). Newbury Park, CA: Sage.

Suwa, M., Purcell, T., \& Gero, J. (1998). Macroscopic analysis of design processes based on a scheme for coding designers' cognitive actions. Design studies, 19(4), 455-483.

Tan, A. R., Matzen, D., McAloone, T. C., \& Evans, S. (2010). Strategies for designing and developing services for manufacturing firms. CIRP Journal of Manufacturing Science and Technology, 3(2), 9097.

Toh, C. A., \& Miller, S. R. (2015). How engineering teams select design concepts: A view through the lens of creativity. Design Studies, 38, 111-138.

Ulrich, K., Eppinger, S., 2011, Product design and development (5th edition). McGraw-Hill: Irwin. 
Wierzbicki, A., Makowski, M., \& Wessels, J. (Eds.). (2000). Model-based decision support methodology with environmental applications (p. 475). Dordrecht, The Netherlands: Kluwer Academic.

Yin, R. K. (2013). Case study research: Design and methods. Sage publications. 